AsCLePIO. Revista de Historia de la Medicina y de la Ciencia

66 (2), julio-diciembre 2014, p061

ISSN-L:0210-4466

http://dx.doi.org/10.3989/asclepio.2014.25

\title{
O TRATAMENTO DOS DOENTES INSANOS DE VILA VIÇOSA NO HOSPITAL DE RILHAFOLES (SEGUNDA METADE DO SÉCULO XIX)
}

\author{
Maria Marta Lobo de Araújo \\ Instituto de Ciências Sociais. Universidade do Minho - Portugal \\ martalobo@ics.uminho.pt
}

Recibido: 6 febrero 2014; Aceptado: 19 mayo 2014.

Cómo citar este artículo/Citation: Araújo, Maria Marta Lobo de (2014), "O tratamento dos doentes insanos de Vila Viçosa no hospital de Rilhafoles (segunda metade do século XIX)", Asclepio, 66 (2): p061. http://dx.doi.org/10.3989/asclepio.2014.25

RESUMO: Neste trabalho analisamos os trâmites processuais respeitantes ao envio de doentes insanos de Vila Viçosa para o hospital de Rilhafoles, na segunda metade do século XIX, e as relações estabelecidas com o hospital desta vila alentejana relativamente ao pagamento do tratamento.

A braços com uma grave crise financeira, o hospital de Vila Viçosa recusava sistematicamente a responsabilidade de enviar os alienados para Rilhafoles, numa tentativa de passar esse ónus para a administração do concelho, mostrando-se muito renitente no pagamento das faturas que lhe chegavam do hospital de São José. 0 conflito entre as duas instituições chegou ao monarca e sem outra alternativa que a do pagamento, o hospital da vila alentejana procedeu ao envio de parcelas de dinheiro, ainda que de forma muito atrasada.

Para a realização deste trabalho servimo-nos dos livros de atas da Misericórdia e do fundo do Governo Civil de Évora, custodiadas pelo Arquivo Distrital da mesma cidade. Estas fontes resultam essencialmente da correspondência estabelecida entre a Misericórdia de Vila Viçosa, o administrador do concelho e o governador civil de Évora.

PALAVRAS-CHAVE: Insanos; Hospital; Pagamento; Vila Viçosa; Rilhafoles.

\section{THE TREATMENT OF THE INSANE PATIENTS AT THE HOSPITAL IN VILA VIÇOSA RILHAFOLES (SECOND HALF OF THE NINETEENTH CENTURY)}

ABSTRACT: In this work we examined the procedural requirements related to the sending of insane patients of Vila Viçosa to the hospital of Rilhafoles, in the second half of the 19th century, and the relationships established with the hospital of this Alentejo town relating to the payment of treatment.

Faced with a severe financial crisis, the hospital of Vila Viçosa systematically refused the responsibility to send the insane patients to the Rilhafoles hospital in an attempt to pass this burden on the administration of the county, being very reluctant to pay the bills that came to him from the hospital of São José. The conflict between the two institutions came to the monarch with no other alternative than the payment, the hospital of village of the Alentejo region proceeded to sending parcels of money, albeit way too late.

For the realization of this work we use the books of the Misericórdia and the documents of the Civil Governor found of the city of Évora under the custody of the Distrital Archive of the same city. This documents results, basically, from the correspondence between the Misericórdia of Vila Viçosa, the council administrator and the civil governor of Évora.

KEY WORDS: Insanes; Hospital; Payment; Vila Viçosa; Rilhafoles.

Copyright: () 2014 CSIC. Este es un artículo de acceso abierto distribuido bajo los términos de la licencia Creative Commons Attribution-Non Commercial (by-nc) Spain 3.0. 


\section{INTRODUÇÃO}

Em 1510, o hospital de Vila Viçosa (Alentejo), propriedade da Casa de Bragança, foi incorporado na Santa Casa por ordem do duque D. Jaime, tendo ao longo da Idade Moderna recebidos grandes benefícios da Casa senhorial. Durante o tempo que residiram em Vila Viçosa, os duques trataram o hospital como se lhes continuasse a pertencer, beneficiando-o com legados, dinheiro, mas também com outras regalias. Essa situação era facilitada não somente por serem irmãos da Santa Casa, mas sobretudo pela relação que mantinham relativamente à administração desta instituição. Os duques interferiam diretamente na gestão da Misericórdia, mandando em todos os seus setores de atividade. Esta relação alterou-se em 1640 quando o duque foi para Lisboa ocupar a Coroa.

Com os legados recebidos, o hospital foi crescendo mantendo no século XVIII seis enfermarias: uma para doentes de febres, outra para doentes de feridas, duas para tratamento do gálico, mais uma para religiosos e envergonhados e ainda outra para convalescentes, ou seja, nesta altura era uma instituição de média dimensão.

Os trabalhos existentes sobre a temática da história da loucura e da psiquiatria em Portugal para o século XIX não se têm preocupado com a maneira como os poderes públicos e os particulares se organizaram para proporcionar o tratamento aos doentes. São ainda mais escassos os que abordam as ligações entre os hospitais das Misericórdias e o hospital de Rilhafoles. O nosso estudo procura ser um contributo para a análise do papel das Misericórdias no estudo da loucura, dando visibilidade às relações estabelecidas entre estas confrarias, as famílias, o hospital da capital e os poderes locais, nomeadamente o administrador do concelho. Neste sentido, o nosso trabalho constitui uma novidade. Deve ainda acrescentar-se que se trata do primeiro trabalho que aborda a assistência prestada aos loucos no hospital de Vila Viçosa. Sublinhe-se, contudo, que considerada a importância da temática para a história da loucura e da psiquiatria, a análise da assistência aos loucos nos hospitais das Misericórdias portuguesas constitui, no nosso entender, um campo de análise a privilegiar.

\section{O HOSPITAL DE VILA VIÇOSA E O TRATAMENTO AOS INSANOS}

A clientela do hospital de Vila Viçosa era maioritariamente constituída por homens de fora, que das diversas partes do país cumpriam na região temporadas de trabalho ${ }^{1}$, por militares, a partir de 1660, quando a Santa Casa assinou um acordo com a Coroa para os curar, e por gente da terra.

A partir de meados do século XIX, surgiu no hospital um outro tipo de doentes: os insanos. Desconhece- mos se já anteriormente o hospital tinha sido confrontado com a necessidade de dar resposta a estes doentes, mas o facto de não ter sido deixado rasto nas fontes impossibilita afirmações seguras. Estamos, no entanto, em crer que só por volta dessa data se viu a braços com esta dificuldade, pois até então, os portadores de perturbações mentais eram mantidos em casa ou, em situação mais grave, mandados encarcerar. A documentação preservada sobre a cadeia da vila para a Idade Moderna também não refere o encerramento de doentes mentais, ao contrário do verificado em algumas localidades².

Com os avanços da ciência médica foi dada mais atenção aos assuntos do foro psiquiátrico, surgindo a Psiquiatria e os hospitais psiquiátricos. Seguindo a linha de pensamento da época, os loucos deviam ser afastados e internados por constituírem elementos perturbadores ao funcionamento da sociedade (Perira, 1986, p. 86).

Em toda a Europa, o desenvolvimento e a implantação dos hospitais psiquiátricos levaram ao afastamento destes doentes dos restantes indivíduos também internados, com vista a proporcionar-lhes um tratamento considerado adequado (Pichot; Barahona, 1984, p. 18).

O primeiro hospital destinado ao tratamento de alienados em Portugal, como eram chamados ou loucos, foi o de Rilhafoles, erigido em 1848. Este hospital estava sob a administração do hospital de São José. Como só existia este hospital a nível nacional, Rilhafoles recebia doentes enviados de todo o país. Só em 1883 surgiu no Porto o hospital Conde Ferreira, possibilitando o envio de doentes também para esta unidade de tratamento.

Durante a segunda metade do século XIX, a Santa Casa de Vila Viçosa foi confrontada com vários casos de pedidos de ajuda por parte das famílias dos doentes do foro psiquiátrico. A Misericórdia manifestava sempre grande desconforto com este tipo de solicitações, pois não reunia condições para os tratar no seu hospital, mas reconhecia a impossibilidade de algumas famílias os manterem em casa. Alegava não os poder ter internados, devido à falta de condições para cuidar da sua doença, considerando que a solução passava pelo seu envio para um dos hospitais psiquiátricos entretanto construídos. Reconhecia, no entanto, que essa medida trazia custos para quem assumia a responsabilidade de os enviar. Por esta razão, o dilema era grande e nem sempre de resolução imediata. Perante a complexidade do problema, alguns doentes mantinham-se alguns dias mais no hospital de Vila Viçosa, aguardando que fosse encontrada uma saída para o seu caso.

O drama era maior quando as famílias não os desejavam ter em sua companhia. Essas situações re- 
feriam-se a casos de familiares idosos ou a doentes, com manifesta incapacidade de os cuidar, ou doentes que pelas perturbações causadas em casa e na rua, precisavam de serem internados para não inquietarem a ordem pública ${ }^{3}$.

A maioria dos enviados pelo hospital de Vila Viçosa para tratamento foi direcionada para Rilhafoles, mas alguns casos dirigiram-se para o hospital Conde Ferreira, provavelmente porque a unidade de tratamento de Lisboa recebia um número muito elevado de doentes, esgotando a sua capacidade de receção. Como já referimos, ao hospital de Rilhafoles chegavam doentes provenientes de todo o país ${ }^{4}$. 0 volume de insanos chegados a Rilhafoles cresceu de tal forma que na década de 60 era já superior à capacidade de receção que possuía, pondo em causa os cuidados de saúde ministrados (Santos, 2011, p. 72).

Como até ao século XIX não existiam em Portugal hospitais para tratar estes doentes, as soluções encontradas eram escassas, embora o hospital de S. José operasse com uma enfermaria para doentes mentais desde o século XVI (Sena, 1943, p. 63; Abreu, 2009, p. 109.114). Também no hospital de D. Lopo de Almeida, no Porto, existia, em meados do século XVII, um espaço destinado a recolher os insanos (Pina, 1964, p. 472).

O envio destes doentes para as novas unidades de tratamento era reclamado pelo progresso das ciências médicas e pela Psiquiatria (Pereira, 1986, pp. 87-88), todavia, como estavam localizadas apenas em duas cidade, os que residiam mais longe tinham de percorrer muitos quilómetros em vários dias de viagem até serem internados. Os moradores em Vila Viçosa faziam algumas centenas de quilómetros até ao Porto e mais de $100 \mathrm{Km}$ até Lisboa, o que dificultava e encarecia o processo de envio. Pela maior proximidade, foram quase todos direcionados para Lisboa.

Em Vila Viçosa, o hospital não se mostrava disponível para receber estes doentes, todavia, também não queria ser acusado de falta de assistência, numa altura em que os olhos do poder central e local se mantinham muito vigilantes e próximos. Sempre que Ihe chegava algum caso, o incómodo era grande. Os irmãos alegavam de forma recorrente a falta de um espaço adequado para os recolher, facto que levou o administrador do concelho em 1870 a recomendar a construção de um compartimento que lhes fosse destinado ${ }^{5}$

A criação de espaços destinados aos loucos e a necessidade de os isolar dos restantes internados esteve na origem do surgimento de enfermarias próprias em alguns hospitais. Em 1870 a Misericórdia de Viseu mandou construir no seu hospital duas enfermarias para alienados, destinadas a cada sexo um dos sexos (Magalhães, 2011, p. 162).
Como refere Sílvia Cunha terá sido o medo e a insegurança da população que terão funcionado como mecanismos de pressão e levado ao surgimento de “locais próprios para os loucos” (Cunha, 2002, p, 102).

Alegando a carência de um espaço apropriado, os irmãos de Vila Viçosa usaram o argumento do mal-estar que alguns provocavam aos restantes internados para os sacudir. Se por um lado, era preciso protegêlos, por outro deviam cuidar para que não molestassem os restantes internados ${ }^{6}$. Vários doentes hospitalizados queixavam-se à Mesa ${ }^{7}$ da falta de sossego e do barulho causado por alguns desses doentes.

Como não possuíam uma enfermaria para os receber, quando era preciso interná-los até que a sua situação se resolvesse, eram colocados em locais vazios e considerados seguros ${ }^{8}$. A permanência de mais ou menos tempo dos doentes no hospital de Vila Viçosa dependia do entendimento conseguido com o Município ou com a família para os remeter para Lisboa. Estava em causa o pagamento da viagem e estadia que ninguém queria assumir. As despesas eram elevadas e incertas, uma vez que o seu montante dependia do tempo de internamento, o qual era determinado pelos médicos de Rilhafoles. A dúvida levava os confrades de Vila Viçosa a manterem-se muito cautelosos, argumentando com a sua situação financeira para travar qualquer ímpeto mais generoso. Sempre que um novo caso aparecia, as negociações entre a confraria e o administrador do concelho prolongavam-se, na tentativa de combinar esforços com o Município para os enviar para Lisboa. O administrador do concelho mediava a situação entre a família e a Misericórdia e tentava sacudir para a Santa Casa as responsabilidades que a Câmara tinha com os doentes pobres.

O pagamento diário de 240 réis em Rilhafoles, mas sobretudo a incerteza do tempo em que aí ficaria internado cada doente eram os motivos maiores que preocupavam os administradores do hospital, por estarem cientes da despesa que causava, da incapacidade financeira em que se encontravam e da hipoteca futura que deixavam aos seus sucessores. Por outro lado, a Santa Casa encontrava-se numa situação duplamente penalizadora: era pressionada pelo administrador concelhio a prover assistência a estes doentes e, ao mesmo temo, por ele fortemente repreendida e vigiada para refrear os gastos.

As hesitações dos irmãos prendiam-se com a preocupante situação financeira da Misericórdia. Arrastando dívidas e somando défices desde a década de 30 deste século, a Santa Casa experimentou momentos de grande aflição, por falta de verbas, sendo obrigada em 1860 a recorrer ao crédito de um banco portuense, a baixar radicalmente os salários dos seus empregados, a reduzir o número de internados no hospital e a cortar gastos em todos os setores para 
não fechar as suas portas e, mesmo assim, por várias vezes esteve na iminência de insolvência. A sua situação financeira foi tão frágil ao longo de quase todo o século XIX que qualquer desatenção no setor das despesas, aumentava o défice já existente, provocava chamadas de atenção do administrador do concelho e do governador civil de Évora e em casos extremos levou à demissão da Mesa e à nomeação de uma Comissão Administrativa. A incapacidade de cobrar os foros, rendas e pensões, o corte dos benefícios provenientes da Casa de Bragança, a inflação galopante e as despesas crescentes no setor da saúde mantiveram esta confraria com défices durante quase toda a monarquia constitucional.

A portaria de 1864 atribuía ao Município a responsabilidade de encontrar uma solução adequada para os casos dos doentes pobres ${ }^{9}$, razão que levou a Misericórdia, por várias vezes, a chamar os seus familiares, advertindo-os para o facto e incentivando-os a solicitar essa intervenção. Todavia, essa estratégia nem sempre surtiu efeitos, porquanto também a Câmara estava com os cofres vazios e interessada em diminuir as suas responsabilidades financeiras. Assistia-se então a um esgrimir de argumentos entre as duas instituições ${ }^{10}$ que em nada beneficiavam o doente e só serviam para arrastar o processo e o seu envio para Lisboa.

A forma como o hospital lidou com esta situação dependeu em muito de cada caso e das condições criadas quer pela Câmara, quer pela família.

A esposa de Manuel António Pirão pediu à Misericórdia a sua deslocação para o hospital de Rilhafoles, afirmando pagar a deslocação, pois já tinha vendido os móveis que possuía para arcar com essas despesas. A senhora afirmava não reunir condições em casa para lidar com os seus ataques de fúria ${ }^{11}$, os quais eram cada vez mais gravosos e frequentes. Por outro lado, como não o conseguia manter na residência, este circulava pelas ruas da vila, ameaçando os transeuntes e inquietando a vida pública. Era competência do administrador do concelho evitar a divulgação dos doentes mentais pela povoação ${ }^{12}$, razão que levava a Misericórdia a escudar-se nos poderes públicos para não tomar posição, aconselhando a peticionária a dirigir-se à Câmara para esta a ajudar. Na eventualidade da sua súplica não ser atendida, como veio a acontecer, o caminho a percorrer seria o do administrador do concelho ${ }^{13}$. A portaria de quatro de maio de 1850 estabelecia que os administradores dos conceIhos não podiam prover a transferência de um doente mental para um hospital contra vontade da família, quando esta decidia responsabilizar-se por ele ${ }^{14}$, mas este não era o caso do citado Manuel António Pirão. Já a portaria de 29 de maio de 1850 previa que fossem as Misericórdias a assegurar o tratamento dos aliena- dos pobres e as despesas da sua remoção para os hospitais psiquiátricos ${ }^{15}$. Apesar disso, a Misericórdia de Vila Viçosa insistia na falta de condições financeiras para o poder fazer e tentava que a administração do concelho assegurasse esses gastos.

Como referimos, a posição da Santa Casa foi mais ou menos inflexível, embora nunca se negasse a comparticipar. Quando existiam alguns bens familiares, a confraria adiantou dinheiro, para posteriormente ser ressarcida, embora nem sempre o reembolso se tenha efetuado de forma fácil ${ }^{16}$.

Se os enfermos não apresentavam quadros clínicos agressivos e era possível conviver com eles, a própria confraria acedia a recebê-los, ainda que temporariamente ${ }^{17}$.

Quando em finais de 1882 a Mesa debateu o caso da alienada Agostinha Maria, que tinha entrado "provisoriamente" no hospital, decidiu ouvir o médico para melhor avaliar o seu estado de saúde e mais sustentadamente tomar uma decisão. As declarações do profissional de saúde foram no sentido da sua transferência para outra unidade de tratamento, por não apresentar sinais de recuperação e por não poder ser ali tratada. Este era o argumento correntemente utilizado pelo médico que os irmãos replicavam sempre que era necessário. O hospital não tinha, segundo ele, recursos materiais de que se destacava a existência de "uma casa de banhos" para a poder manter. Perante esta situação, a Mesa decidiu enviá-la para o hospital de Rilhafoles, assumindo as despesas do transporte e do seu tratamento ${ }^{18}$. Todavia, quando no ano seguinte foi contactada para proceder ao pagamento, procurou esquivar-se, o que obrigou o mordomo-mor de São José a recordar-lhe a lei, responsabilizando-a pelos custos do seu internamento ${ }^{19}$

Os tratamentos disponibilizados pelo hospital de Vila Viçosa reproduziam algumas das alterações conhecidas na ciência médica, mas estavam longe dos avanços que esta tinha alcançado na Europa, sobretudo na segunda metade oitocentista e que eram praticados no hospital de Rilhafoles ${ }^{20}$.

Como a Santa Casa mostrava relutância em ter este tipo de doentes no seu hospital, por não ser o local adequado para o seu tratamento, e despachava-os logo que podia, as famílias que os conseguiam ter em sua companhia optavam por essa solução ${ }^{21}$.

A dificuldade das famílias lidarem com estes doentes estava, por um lado, associada à pobreza e à incapacidade financeira de suportarem uma pessoa que não contribuía para o rendimento da casa e, por outro, às próprias características da doença, que em certos casos tornava os atingidos violentos e causadores de perturbações familiares e na comunidade (Chevalier, 2007, pp, 334.338). Os isanos eram considerados 
perturbadores do sossego particular e público (Silva, 2008, pp. 2-3). Existe, porém, um terceiro motivo a considerar, que se prende com a representação social da doença. Assumir publicamente a loucura de uma pessoa querida e enviá-la para um hospital especializado na doença, nem sempre era socialmente bem visto pelos que tinham a responsabilidade de tomar essa decisão. A loucura era uma doença que estigmatizava muito e, por esta razão, motivo de grande hesitação no momento de decidir enviar os seus portadores para os "hospitais de loucos".

Quando a incapacidade financeira do hospital se associava ao desejo da família em não querer manter os doentes em casa, o problema agravava-se como se registou em alguns casos. A Misericórdia recebia os doentes por uns dias, mas sempre na esperança de Ihes dar um outro rumo. O caso da doente Maria Joana torna-se exemplificativo desta situação em 1886, agravado ainda pela "repugnância" do marido em enviá-la para o referido hospital psiquiátrico.

A loucura foi durante muito tempo entendida como uma doença masculina. Só a partir do século XVIII se "feminizou" (Porter, 1989, p. 148). O caso de Joana Maria arrastou-se ao longo de vários meses, desesperando os próprios mesários que não encontravam uma saída para esta doente, enquanto o marido "vacilava e contradiz-se nas suas resoluções" 22. Na ausência de desenvolvimentos favoráveis entre o provedor e o marido da doente, foi solicitada a sua presença numa sessão da Mesa para explicar perante o órgão as suas razões. Joaquim Pereira informou ser pobre e não poder ter a esposa na sua companhia, por estar impossibilitado financeiramente. Perante a situação e devido aos constrangimentos vividos com o hospital de Rilhafoles, a Mesa resolveu estudar as condições de envio da doente para o hospital Conde Ferreira, uma vez que o casal possuía alguns bens ${ }^{23}$. Esta solução não veio, contudo, a acontecer.

Sem a poder manter no hospital e perante a situação criada pela própria família da doente, a Misericórdia informou o governador civil, o qual intimou o marido a levá-la para o seu domicílio ${ }^{24}$.

Perante as dificuldades apresentadas, parece evidente a forma como os poderes públicos, as instituições particulares e os familiares se movimentavam no sentido de alcançarem uma solução para o problema, embora nem sempre com a celeridade que a situação exigia, penalizando os doentes.

Quando os familiares eram detentores de bens, a Misericórdia procurava esgotar a possibilidade destes assumirem todas as despesas, embora os processos nem sempre fossem lineares. Sempre que se verificava um novo caso, a Misericórdia entrava em contacto com o administrador do concelho para o colocar ao corrente e interagia com a família na tentativa de ser encontrada uma solução, o que nem sempre se verificava. Em alguns casos, foi sugerido pelo administrador do concelho que a Misericórdia assumisse a responsabilidade do envio do doente para Lisboa, como aconteceu em 1877 com João Dionísio, recebendo em contrapartida bens para saldar as despesas. Estas propostas eram efetuadas após consulta e entendimento com a família, que se responsabilizava por parte das despesas. Como sempre acontecia, o representante local do governo procurava que a Santa Casa assumisse a maior parte ou a totalidade da responsabilidade, causando sempre muito mal-estar na instituição, como se verificou neste caso. A Misericórdia responsabilizou-se apenas pelo pagamento dos gastos, depois da mãe do doente ter esgotado os seus rendimentos ${ }^{25}$.

A grave situação financeira da Santa Casa não permitia descuidos e obrigava os mesários a exigências com os familiares e com os poderes públicos, todavia, usava de misericórdia sempre que podia e procurava não colocar em perigo o precário equilíbrio de muitas famílias ${ }^{26}$.

\section{OS PAGAMENTOS AO HOSPITAL DE RILHAFOLES}

Estes doentes obrigaram a Misericórdia de Vila Viçosa a manter relações frequentes com o hospital de São José, administrador do hospital de Rilhafoles. Os contactos foram marcados por grande tensão, devido à falta de disponibilidade financeira do hospital alentejano para efectuar os pagamentos respeitantes aos tratamentos dos doentes para lá enviados.

O hospital lisboeta recebia os enfermos, mas sob condições, isto é, quem os remetia assumia o pagamento do tratamento. Por isso, havia muita ponderação no seu envio e nem sempre prontidão e vontade de pagar as despesas efetuadas com eles.

As relações com o hospital de São José pautaramse nas décadas de 70 e 80 por constantes pedidos de pagamento por parte deste hospital e de estratégias nem sempre muito percetíveis, delineadas pelo hospital alentejano, na tentativa de o retardar ou de lhe fugir, usando variadas desculpas.

Aos constantes pedidos de reembolso pelas despesas efetuadas, a Misericórdia de Vila Viçosa questionava a seriedade da entidade emissora, mostrando-se indisponível para assumir as despesas.

Como não se podia estimar o prazo de melhoras dos doentes enviados, a Santa Casa alentejana mostrava-se inquieta e preocupada. Quando não conseguia avaliar o tempo, entrava em contacto com o enfermeiro-mor do hospital lisboeta, solicitando-Ihe uma avaliação dos médicos para que pudesse prever a possibilidade dos enfermos serem removidos para 
Vila Viçosa ${ }^{27}$ e, desta forma, diminuir os custos do tratamento.

Decorridos 10 anos de conflito aberto entre a Misericórdia de Vila Viçosa e o hospital de São José sobre a despesa efetuada com os doentes, "mal recebidos", como afirmavam os mesários da vila alentejana, estes afirmaram-se credores do cumprimento integral da lei e decidiram não pagar. Declaravam que perante a portaria de 17 de Janeiro de 1851, que regulamentou a entrada dos doentes no hospital de São José apenas com carta de guia, não mais os enviaram para esta instituição.

A circular de 23 de janeiro de 1866 do governador civil de Évora recomendava, de acordo com a portaria de 20 de janeiro do mesmo ano, que as Misericórdias não remetessem enfermos ao hospital de São José sem serem acompanhados de cartas de guia e que o mordomo-mor deste hospital remetesse todos os anos económicos as despesas em débito às instituições responsáveis pelo envio dos doentes para estas as incluírem nos orçamentos ordinários anuais ${ }^{28}$.

Inconformada, a Misericórdia contestava a interpretação da portaria de 1851 por parte do hospital, acusando-o de receber mendigos sem residência em Vila Viçosa.

Perante as respostas que chegavam de Vila Viçosa, e como não podia deixar de receber, o hospital de São José passou ao ataque e queixou-se junto das autoridades competentes. Em 1877, a Mesa recebeu ordem do Conselho de Distrito para pagar ao referido hospital, levando os mesários a efetuar esse pagamento sob protesto ${ }^{29}$. O ofício recebido do administrador do concelho ordenava ao provedor a inclusão de 96.960 réis no orçamento para enviar para o hospital de Lisboa, mas a Misericórdia respondia não lhe caber essa despesa, por não ter passado as cartas de guia aos doentes mencionados. Perante a insistência do mordomo-mor do referido hospital, esclareceu-o que tinha recorrido ao monarca para ser ele a resolver a questão $0^{30}$. A Santa Casa de Vila Viçosa mantinha-se esperançada na clemência do monarca, mas também na ligação que sempre teve à Casa de Bragança.

Contra a portaria de 1850 estava também o administrador do concelho que lhe ordenou a inclusão no orçamento para 1867 de uma verba destinada a São José, facto que enfureceu os mesários, afirmando fazêlo apenas por obediência, embora não se coibissem de fazer ouvir o seu protesto e, em 1874, passaram novamente ao ataque. Acusaram o hospital de São José de forjar as cartas que guia que apresentava como prova, fazendo-o com depoimentos orais dos mendigos que se diziam residentes no concelho alentejano visado (Araújo, 2010, p. 174). Na altura, os mesários esmeraram-se em argumentos sobre a passagem das cartas de guia, tendo recorrido a um advogado para sustentar a argumentação sobre a validade dos testemunhos dos mendigos, embora de nada lhes valesse ${ }^{31}$. Com ou sem razão, o facto é que a Santa Casa de Vila Viçosa não dispunha de lastro financeiro para tais pagamentos e procurava fugir-lhes por todos os meios.

Em 1878, a Misericórdia foi obrigada, como já referimos, através de ordem régia, a pagar ao hospital de São José e não o podendo fazer de uma vez somente, enviou uma parcela 78.084 réis, em julho, através de um vale do correio ${ }^{32}$. O dinheiro remetido era referente aos anos de 1864 a 1869. Na ocasião, e para maior controlo, pediu ao mordomo-mor do hospital de São José para lhe enviar um mapa com os doentes a que se referia o pagamento, desde 1864. Tratava-se de uma demonstração de força, uma vez que a Santa Casa entendia não dever efetuar essas despesas e só as começou a pagar porque foi obrigada. Como não obteve resposta, a Mesa acusava-o de falta de conhecimento das regras de civilidade e educação, pedindo ao governador civil para o obrigar a remeter a documentação solicitada ${ }^{33}$. A Misericórdia duvidava ter responsabilidades no pagamento e declarava apenas ter cumprido uma exigência, não deixando, contudo, de o fazer sem protesto. O que mais indignava a Santa Casa alentejana era a arrogância do hospital da capital que, segundo a Mesa, se encontrava escudado na "protecção superior que devida á natureza d'esse Estabelecimento Ihe é despensada"34. Esta acusação está provavelmente associada ao facto da sua súplica junto do monarca não ter alcançado uma resposta positiva, como era sua expetativa. O hospital de Vila Viçosa reconhecia a sua pequenez perante o de São José, enquanto pensava também nas vantagens de estar próximo do poder político.

O hospital de Lisboa usava a Misericórdia e a Câmara de Vila Viçosa, procurando, de um ou de outro lado, ser ressarcido das despesas feitas. Em agosto de 1879 escreveu uma carta ao presidente da Câmara referindo o alvará de 14-02-1825 que responsabilizava estas instituições de remeterem para o hospital o dinheiro referente ao curativo dos doentes para lá enviados dos respetivos concelhos e acusando a Santa Casa de Ihe dever 125.040 réis referentes aos anos de 1878 e 1879 , montante que devia ter sido pago no anterior mês de junho. Acusava ainda a Misericórdia de ter desviado esse dinheiro para as obras realizadas na sua farmácia ${ }^{35}$. Apesar do atraso, a Santa Casa respondeu em abril só poder satisfazer o referido montante no próximo mês de junho ${ }^{36}$. Esta resposta servia apenas para arrastar o pagamento e passar a responsabilidade para a nova Mesa. Assim, quando tomou posse, o provedor em funções informou o hospital de São José de não dispor de verbas para efetuar o pagamento e necessitar de um orçamento suplementar para o poder concretizar ${ }^{37}$. 
A posição da Santa Casa de Vila Viçosa foi sempre a de utilizar subterfúgios para não enviar prontamente o dinheiro para o hospital da capital. Se por um lado, não dispunha de verbas e vivia em permanente aflição económica, por outro recorria a estratagemas dilatórios, exasperando o hospital de Lisboa. O provedor sabia bem que para pagar tinha de introduzir a quantia a enviar ao hospital de São José no orçamento para o próximo ano. Se não o fizesse, como aconteceu, o seu sucessor não a podia pagar, a não ser através de um orçamento retificativo, como prometeu fazer. Todavia, em julho quando respondeu não o podia efetuar, por estar a chegar ao poder e o orçamento ordinário ter acabado de ser aprovado.

Em 1879, a Misericórdia procedeu, de facto, a melhoramentos na farmácia e pediu à Câmara que Ihe cedesse vários materiais do extinto convento de São Paulo ${ }^{38}$

A obra foi realizada com estas ajudas, mas necessitou da aprovação de um orçamento suplementar por parte das autoridades competentes, uma vez que excedeu os gastos orçamentados, devido aos seus custos terem sido mal avaliados pelos peritos. Apesar do esforço financeiro, as obras só foram terminadas com um donativo oferecido pelo escrivão da Mesa.

Com a remodelação efetuada, a farmácia melhorou bastante, não apenas em bens interiores, mas também com a abertura de uma porta para a rua de Três e outra para o pátio do hospital ${ }^{39}$

Se o dinheiro que devia ter ido para Lisboa foi desviado para estas obras não o podemos afirmar com segurança, todavia, o hospital da capital parecia estar bem informado do que se passava na vila alentejana e solicitava ao presidente da Câmara o cumprimento da lei.

Perante a falta de pagamento, o mordomo-mor do hospital de São José escrevia mensalmente ao presidente da Câmara lembrando a dívida em causa e solicitando que pressionasse a Misericórdia, avisando-o mesmo das iniciativas que devia tomar junto do governador civil, para resolver o assunto ${ }^{40}$.

Como já referimos, as contas enviadas pelo hospital de São José eram mal recebidas em Vila Viçosa e os mesários insurgiam-se contra Lisboa, protestando contra a atuação do seu mordomo-mor e responsabilizando-o por atos que lhe eram acometidos.

Em 1880 numa carta enviada ao provedor da Misericórdia, o hospital de São José fazia saber que estavam pagamentos por realizar referentes a 1875 e 1876, muito embora tivessem sido já outros realiza- dos e enviado o recibo correspondente a 1874, 1875 e $1876^{41}$. A missiva tornava clara a tensão existente entre as duas instituições, mas também os pagamentos parcelares e retardados realizados pela Santa Casa de Vila Viçosa.

Mas se a Misericórdia tardava em responder e em pagar, a Câmara replicava igual procedimento, o que exasperava o mordomo-mor. Em setembro de 1880 escreveu ao administrado do concelho de Vila Viçosa, pedindo resposta a vários ofícios enviados e solicitando que as despesas relativas aos doentes idos do concelho fossem incluídas no orçamento camarário ${ }^{42}$. A receção de doentes de todo o país e a dificuldade que tinha em cobrar as despesas tornou o hospital de São José mais reivindicativo e menos tolerante à demora $^{43}$. As explicações dadas pelo mordomo-mor em nada ajudavam a Misericórdia da vila alentejana, que apesar de melhor informada, não conseguia meios para também ela responder com eficácia às solicitações feitas. Em 1882 as cartas que chegavam de Lisboa a Vila Viçosa informavam da falta de verbas com que se confrontava o hospital de Rilhafoles e a necessidade que tinha de socorrer "1800" pacientes diariamente. Por isso, em junho de 1882, a carta enviada ao provedor solicitava o pagamento da dívida desse ano num prazo de oito dias ${ }^{44}$.

\section{CONCLUSÃO}

As relações entre o hospital de São José e a Misericórdia de Vila Viçosa foram pautadas nesta segunda metade do século XIX por grande tensão devido à falta de pagamento ou ao envio apenas de parcelas do montante referente ao curativo de doentes. Sem recursos financeiros que sustentassem essa despesa, a Santa Casa alentejana procurou por todos meios esquivar-se ao pagamento, levantando dúvidas e afrontando o hospital da capital, numa tentativa de ganhar tempo, mas também procurando esgrimir argumentos que lhe diminuíssem a conta a saldar. Esta estratégia levou-a até ao monarca, pedindo ajuda e proteção, mas sem conseguir vencer, viu-se obrigada a pagar a sua dívida, fazendo-o de forma muito arrastada e parcelar.

Como em Rilhafoles se recebiam doentes provenientes de todo o país, o hospital de São José mantinha-se muito vigilante e dispunha de experiência acumulada que o fazia direcionar os seus pedidos para várias pessoas e instituições, numa luta permanente para ele próprio saldar as suas dívidas e continuar a tratar os muitos doentes insanos diariamente internados. 


\section{NOTAS}

1 O mesmo se passou também no hospital do Espírito Santo de Évora. Leia-se Pardal (2013), pp. 80-83.

2 Sobre o encerramento dos loucos nas cadeias leia-se Foucault (2002); Álvarez-Uría (1983, pp. 26-27; Esteves (2010), pp. 701-709.

3 Na tentativa de os controlar, algumas famílias mais abastadas isolavam estes doentes num compartimento da casa. Veja-se Pereira; Gomes; Martins (2005), p. 99.

4 Para esta matéria consulte-se Pichot; Barahona (1984), p. 254

5 Arquivo Distrital de Évora, (doravante ADE), Fundo do Governo Civil, Orçamentos de receita e despesa de 1870-1871, cx. 984, peça no 33 , fl. 5 .

6 Na Idade Moderna não era raro estarem acorrentados para que não prejudicassem os que se encontravam à sua volta. Veja-se Tropé (1994), pp. 239-242.

7 Órgão diretivo composto por 13 membros. A Mesa tinha um mandato anual

8 Em 1869, o alienado Angélico Martins foi removido para o local denominado "receituário", por ser o único compartimento isolado que reunia condições de segurança para o ter.

9 Arquivo Municipal de Vila Viçosa (doravante AMVV), Fundo da Misericórdia, Livro das Actas das Sessões da Comissão Administrativa da Misericordia de Villa Viçosa 1857-1860, fls. 21v.-24. Sobre a condição social dos doentes internados no hospital de Cabeceiras de Basto em finais do século XIX e começos do XX veja-se Ferraz (2011), pp. 103-106.

10 A propósito da atitude da sociedade perante estes doentes leiase Rosen, Gorge (1974, pp. 214-227.

11 Alguns doentes tinham ataques coléricos que amedrontavam os que conviviam com eles. Leia-se Mattos (1889), p. 81.

12 Confira-se Código Administrativo de 1842 (1849), Coimbra, Imprensa da Universidade de Coimbra, p. 108

13 AMVV, Fundo da Misericórdia, Servirá este Livro para as Actas das Sessoes da Administração da Misericordia de Villa Viçosa 1868-1877, fls. 37v., 39v., 41

14 Collecção Official de Legislação Portuguesa redigida por José Maximo de Castro Neto Leite e Vasconcellos, do Conselho de Sua Majestade e Juiz da Relação de Lisboa, Anno de 1850 (1851), Lisboa, Imprensa Nacional, p. 188.

15 Collecção Official de Legislação Portuguesa redigida por José Maximo de Castro Neto Leite e Vasconcellos, do Conselho de Sua Majestade e Juiz da Relação de Lisboa, Anno de 1850..., p. 221.

16 Os 304.560 réis respeitantes ao tratamento em Rilhafoles do doente Joaquim António das Neves foram pagos pela sua esposa em 30 prestações. Arquivo da Santa Casa da Misericórdia de Vila Viçosa, Livro de receita e despesa 1879-1880, fl. 30.

17 Em 1876 a Misericórdia acordou fazer regressar Ana Joaquina, internada em Rilhafoles, por ter notícia que o seu estado de saú- de não era preocupante. AMVV, Fundo da Misericórdia, Servirá este Livro para as Actas das Sessoes da Administração..., 18681877 , fl. 138 . Depois de estar na vila, a doente foi internada no hospital, mas como a Misericórdia não a desejava manter, pediu por três vezes ao administrador do concelho que diligenciasse uma solução para o seu caso. AMVV, Fundo da Misericórdia, Copiador dos oficios expedidos..., fls. 68v.-69, 74v.-75, 77

18 AMVV, Fundo da Misericórdia, Servirá este Livro para as actas das sessões da Mêza administrativa da Misericordia de Vila Viçosa 1882-1896, fl. 9v.

19 Agradeço à Profa Laurinda Abreu a consulta documental efetuada na Torre do Tombo, referente ao arquivo do hospital de São José. Arquivos Nacionais da Torre do Tombo, (doravante ANTT), Livro do hospital de São José, no 2469, registo no 538 .

20 Consulte-se a propósito Sournia (1995), pp. 251-285

21 Joaquim António Correia Fusco solicitou em 1886 uma ração diária à Misericórdia para o seu filho, doente mental, por ser pobre, "viver apenas do seu trabalho" e não ter recursos suficientes para sustentar a sua família. A Mesa deferiu o pedido, estabelecendo, no entanto, que a ajuda se mantinha apenas durante a sua vigência. AMVV, Fundo da Misericórdia, Servirá este Livro para as actas das sessões da Mêza..., 1882-1896, fl. 62v.

22 AMVV, Fundo da Misericórdia, Servirá este Livro parar as actas das sessões da Mêza, Servirá este Livro para as actas das sessões da Mêza..., 1882-1896, fls. 63v.-64v.

23 AMVV, Fundo da Misericórdia, Servirá este Livro para as actas das sessões da Mêza..., 1882-1896, fl. 62v.

24 Maria Joana saiu do hospital, mas a Santa Casa continuou a ajudá-la com o envio de uma ração diária, respondendo favoravelmente ao pedido que o seu marido lhe dirigiu. AMVV, Fundo da Misericórdia, Servirá este Livro para as actas das sessões da Mêza..., 1882-1896, fl. 66v.

25 AMVV, Fundo da Misericórdia, Servirá este Livro para as actas das sessões da Mêza..., 1882-1896, fls. 173-173v.

26 Quando em 1887 morreu Joana Felizarda, de Bencatel, doente mental, que a confraria ajudava em sua casa, a Mesa resolveu não cobrar nada aos seus filhos, apesar de possuírem alguns bens, por não desejar "praticar violência" contra eles e considerar que o que lhe enviou era inferior ao que teria gasto se a doente tivesse sido tratada num hospital psiquiátrico. AMVV, Fundo da Misericórdia, Servirá este Livro para as actas das sessões da Mêza..., 1882-1896, fls. 96-96v.

27 AMVV, Fundo da Misericórdia, Servirá este Livro para as Actas das Sessoes da Administração..., 1868-1877, fls. 137v., 139.

28 Collecção Official da Legislação Portugueza, Anno de 1866 (1867), Lisboa, Imprensa Nacional, p. 16.

29 AMVV, Fundo da Misericórdia, Servirá este Livro para as actas das Sessões da Mêza administrativa da Misericordia de Villa Viçosa, 1877-1882, fls. 17-17v.

30 AMVV, Fundo da Misericórdia, Livro de registo dos oficios do copiador..., 1857-1867, fls. 70v.-71, 79-80. 
31 AMVV, Fundo da Misericórdia, Servirá este Livro para as Actas das Sessoes da Administração..., 1868-1877, fls. 140-146v.

32 ADE, Fundo do Governo Civil, cx. 1013, Correspondência em 1979, documento avulso, não paginado.

33 ADE, Fundo do Governo Civil, cx. 1013, Correspondência de 1879, documento avulso, não paginado.

34 ADE, Fundo do Governo Civil, cx. 1013, Correspondência 1879, documento avulso, não paginado.

35 ANTT, Livro do hospital de São José, no 2461, registo no 484.

36 ANTT, Livro do hospital de São José, no 2991, registo no 2125.

37 ANTT, Livro do hospital de São José, no 2991, registo no 118 .
38 AMVV, Copiador dos officios expedidos pela Secretaria da Misericordia de Vila Viçosa-Outubro de 1776 a Março de 1879, fls. 99-100.

39 AMVV, Fundo da Misericórdia, Servirá este Livro para as actas das Sessões da Mêza..., fls. 41v.-42.

40 ANTT, Livro do hospital de São José, no 2461, registos no 863, $1309,1730$.

41 ANTT, Livro do hospital de São José, no 2462, registo no 3931.

42 ANTT, Livro do hospital de São José, no 2462, registo no 206.

43 ANTT, Livro do hospital de São José, no 2462, registo no 1039.

44 ANTT, Livro do hospital de São José, no 2462, registos no 481, 794, 1002.

\section{REFERÊNCIAS BIBLIOGRÁFICAS}

Abreu, Laurinda (2009), "A Misericórdia de Lisboa, o Hospital Real e os insanos: notas para uma introdução". In: Museu São João de Deus: Psiquiatria e História, Lisboa, Província Portuguesa da Ordem Hospitaleira de São João de Deus.

Álvarez-Uría, Fernando (1983), Miserables y loco. Medicina mental $y$ orden social en la España del siglo XIX. Barcelona, Tusquets Editores.

Araújo, Maria Marta Lobo de (2000), Dar aos pobres e emprestar a Deus: as Misericórdias de Vila Viçosa e Ponte de Lima (séculos XVI-XVIII). Barcelos, Santa Casa da Misericórdia de Vila Viçosa; Santa Casa da Misericórdia de Ponte de Lima.

Araújo, Maria Marta Lobo de (2010), A Misericórdia de Vila Viçosa de finais do Antigo Regime à República. Braga, Santa Casa da Misericórdia de Vila Viçosa.

Chevalier, Louis (2007), Classses laborieuses et classes dangereuses. Paris, Éditions Perrin.

Código Administrativo de 1842 (1949), Imprensa da Universidade de Coimbra.

Cunha, Sílvia Maria Fernandes Vilarinho (2002), Razão e Loucura. A perspectiva arqueológica de Michel Foucault. Porto, Faculdade de Letras, Dis. de Mestrado policopiada.

Esteves, Alexandra Patrícia Lopes (2010), Entre o crime e a cadeia: violência e marginalidade no Alto Minho (1732-1870). Braga, Universidade do Minho, Dis. de doutoramento policopiada.

Ferraz, Norberto Tiago Gonçalves (2011), Solidariedades da Misericórdia de Cabeceiras de Basto 1877-1930. Porto, Edição do autor.
Foucault, Michel (2002), Os anormais. São Paulo, Martins Fontes.

Magalhães, Vera Lúcia Almeida (2011), O hospital novo da Misericórdia de Viseu. Assistência, poder e imagem. Maia, Santa Casa da Misericórdia de Viseu.

Mattos, Júlio de (1889), A loucura. Estudos clinicos e medico-legaes. S. Paulo, Teixeira e Irmãos Editores.

Pardal, Rute (2013), Práticas de caridade e assistência em Évora (1650-1750). Universidade de Évora, Dis. de doutoramento policopiada.

Pereira, Ana Leonor (1986), “A institucionalização da loucura em Portugal". Revista Crítica de Ciências Sociais, (no 21).

Pereira, Pedro Teixeira; Eva Gomes y Olga Martins (2005), "A alienação no Porto: o hospital de alienados do Conde Ferreira (1883-1908)", Revista da Faculdade de Letras. História, Porto, III série, (vol. 6).

Pichot P., Fernandes, Barahona (1984), Um século de Psiquiatria e a Psiquiatria em Portugal. Lisboa, Roche.

Pina, Luís de (1964), "Instituições de Bemfazer e actividades culturais". In: Peres, Damião (dir.), A História da Cidade do Porto, vol. II, Porto, Portucalense Editora.

Porter, Roy, História Social de la Loucura. Barcelona, Editorial Crítica, 1989.

Rosen, Gorge (1974), Locura y sociedad. Sociología histórica de la enfermedad mental. Madrid, Alianza Editorial. 
Santos, Nuno Borja (2011), "O hospital de Rilhafoles e o Asilo de Alienados na Europa do século XIX", Revista do Serviço de Psiquiatria do Hospital Prof. Doutor Fernando Fonseca, vol. 9,(n ), Dezembro.

Sena, António Maria de (1943), “Os alienados em Portugal. História e Estatística", Boletim de Assistência Social, nN 2, Abril.

Silva, Maria Olga de Castro e (2008), "Formação e assistência de saúde mental nos séculos XIX e XX, no Hospital Conde Ferrei- ra". In: "Cultura Escolar, Migrações e Cidadania". Actas do VII Congresso Luso-Brasileiro de História da Educação, Porto, s. e.

Sournia, Jean-Charles (1995), História da Medicina, Lisboa, Instituto Piaget.

Tropé, Hélène (1994), Loucura y sociedad en la Valencia de los siglos XV al XVII. Diputación de València. 